\title{
Comparison of Selected Subjects of the Non- profit Sector in the Conditions of the Slovak Republic
}

\author{
Zuzana Rosnerova ${ }^{1, *}$ and Dagmar Hraskova ${ }^{1}$ \\ ${ }^{1}$ University of Zilina, Faculty of Operation and Economics of Transport and Communications, \\ Department of Economics, Zilina, Slovak Republic
}

\begin{abstract}
Non-profit organizations are a specific type of entities in the national economy that significantly helps to improve the living standards of the country's population. The article focuses on the financial performance of entities in the non-profit sector of the Slovak Republic depending on the financial instrument of tax allocation, taking into account the time factor during which the entities operate in the non-profit sector. The aim of the article is to analyse the financial performance of non-profit organizations providing services of general interest and foundations with the subsequent specification of the results of the issue. We work with the hypothesis that in terms of financial performance, foundations will perform better compared to non-profit organizations. Segmentation, comparison and descriptive methods were used in the solved issue. Only in one of the analysed groups did we come to the result that the non-profit organization was able to obtain more funds than the foundation through the tax allocation tool in 2019. In the case of the other groups analysed, foundations were more financially efficient, whose performance significantly exceeded that of non-profit organizations. In terms of market life, based on the analysis, the most efficient organizations were organizations with a market life of 1-5 years and with a longer market life, their financial performance decreased. In the case of foundations, we found that the highest performance is achieved by foundations with a market existence of $15-20$ years. We can therefore state that the established hypothesis was only partially confirmed, although in most cases foundations were more financially efficient.
\end{abstract}

Keywords: non-profit organization, performance of non-profit subject, tax allocation, non-profit sector

\section{Introduction}

In the national economies of countries, there is a certain area of organizations or institutions that deal with specific activities, and ultimately these organizations are very beneficial to certain groups of end users, whom they help in many areas. These are organizations or institutions that belong to the non-profit sector and their existence is linked

*Corresponding author: zuzana.rosnerova@fpedas.uniza.sk 
to their mission. Their basic goal is to cover a certain segment through the direct production of benefits, which takes the form of a service that is provided publicly [1]. Within their scope, non-profit organizations provide a different type of services compared to business entities, the primary difference being that the services are provided without the right to payment [2]. According to Novotny and Lukes, a non-profit organization fills the space that arises between the state, the market and the family and at the same time serves to capture a wide range of civic activities through which it contributes to positive changes in people's way of life [3]. Incentives that precede the emergence of non-profit entities stem from the situation and needs of a particular state, as well as their emergence depends on the motivation of their founders and the purpose for which they will serve. A specific feature that significantly distinguishes these organizations from the group of business entities is the fact that the primary goal of these organizations is not to make a profit, but to provide a service that is characterized by its public benefit characteristics. This means that such a service is provided to the user free of charge [4]. According to the author Tetrevova [5] a non-profit organization performs several functions, which include functions: social, participatory, political, and at the same time economic, informational and educational functions.

The non-profit sector includes several types of non-profit entities, the basic selection of which is offered by the author Rektorik. According to him, the typology of non-profit entities is as follows:

1. private non-profit organizations mutually beneficial,

2. private non-profit organizations of public benefit,

3. non-profit public organizations such as organizational units and contributory organizations of the state, or organizations of self-governing territorial units,

4. other public non-profit organizations,

5. private non-profit organizations such as companies [6].

The Slovak Republic distinguishes the following types of non-profit organizations in terms of legal form: associations, foundations, public benefit organizations and noninvestment funds.

A frequently discussed topic is the issue of financing non-profit organizations, which is very specific in nature. A non-profit organization can make a profit during its operation, but it must never be divided among its founders and must be spent solely on ensuring the mission and purpose of the non-profit subject. The financial factor is also very closely connected with the performance of a non-profit organization and can also fulfill a certain descriptive function in terms of its performance. When dealing with the performance of a non-profit entity, it is possible to take into account to a large extent the amount of funds that the non-profit entity was able to obtain for a specific period for the needs of financing its subsequent operation and maintenance and survival in the market [1]. In connection with the issue of financing, in the environment of non-profit entities we encounter the concept of fundraising. Fundraising is essentially an opportunity for non-profit entities to obtain financial and other resources to ensure their activities using various methods and procedures [7]. In the case of fundraising, the question is addressed as to how it is possible to obtain external support and thus secure resources for self-financing. In their publication, the authors Vrtana and Krizanova describe the importance of spreading enlightenment about his existence and the possibility to convince others of the importance of his activities and how important the organization is for society as such [8]. The goal of fundraising is basically to gain people's interest, their time and their trust. In practice, not only one source is sufficient for the needs of financing a non-profit entity, but the principle of multi-source financing is used. In this case, it is true that the more supporters - donors there is for a nonprofit entity, the better and that is why non-profit entities try to develop multi-source funding to a large extent [9]. In her publication, the author Bartosova mentions as the most 
common sources of financing forms such as monetary donation, which is one of direct support, endowment funds or non-monetary donation [10]. In practice, however, there are often cases where non-profit entities are very burdened by a lack of funding and in general face problems with their funding [11]. The author Valaskova considers behavioural elements of decision-making to be a very important factor in solving financial issues, which can serve as a means to justify why certain market areas are created as inefficient for a nonprofit organization [12].

If we compare the system of financing non-profit organizations and companies, entities of the non-profit sector are at a significant disadvantage in terms of monitoring financial performance. In the case of companies, this performance is easier to monitor and analyse through various financial indicators [13]. The risk of financial distress has a negative impact on their operations both in the case of companies and in the case of non-profit entities [14]. The author Shemyatikhina considers the influence of marketing tools through which non-profit entities can spread awareness about their mission to be an important element in addressing their performance, and in general their performance can be supported [15].

A non-profit entity can be seen as a kind of dynamic structure. This dynamism stems from the fact that the non-profit entity is subject to certain changes that occur in the national economy in which the entity operates and thus constantly evolves and develops, eventually declines and thus responds to stimuli from the environment. Basically, every non-profit entity is characterized by its life cycle. The author Carvalho emphasizes in the life cycle of organizations to focus as much as possible on their responsibility as a key factor in securing their mission, through which they can influence the time of their existence in the market [16].

In his publication, Alani emphasizes the strategic solution to the problematic issues facing the organization, and according to him, through such an approach, the organization can innovate. These are an integral part of the advancement and, in general, the survival of the subject on the market [17]. In connection with the implementation and evaluation of the success of the strategic approach to the issues addressed, the use of artificial intelligence is justified [18].

Based on the specified criteria, it is possible to determine at what stage of development the non-profit entity is and what development trends await it in the future. The life cycle of an organization can be represented by a curve that is compared to the silhouette of an "elephant's back", as shown in the following figure. The horizontal axis shows time and the vertical axis captures qualitative changes - that is, the progress or decline of the organization.

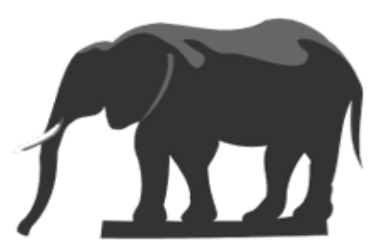

Fig. 1. The elephant's back as the life cycle of a nonprofit organization Source: [19]

The aim of the article is to analyse the performance of selected entities of the non-profit sector through the most striking factor for ensuring the operation - funding through the collection of funds, i.e. through tax allocation as the most important means of financing to ensure the mission of non-profit entities. 


\section{Methods}

In the article we deal with the analysis of the performance of selected subjects of the non-profit sector. As part of the analysis, we decided to compare the performance of selected entities in the non-profit sector, focusing primarily on the financial side of these entities in 2019, which operate in the Slovak Republic. From among the entities of the nonprofit sector, we have chosen two groups of entities of the non-profit sector, namely foundations and non-profit organizations that provide services of general interest. The hypothesis was determined as an assumption that foundations will be stronger in terms of their financial performance. Comparative and descriptive methods were used in this analysis. To carry out the conclusions of the analysis, we selected entities in terms of their time in the non-profit sector in the conditions of the Slovak Republic. In the analytical part, we worked with the available data of these subjects, taking into account the subjects placed in the first three positions from each selection group. The data come from the financial statements of non-profit organizations. The selection groups for performing the analysis are as follows:

- non-profit organizations providing services of general interest and foundations with a duration of 1-5 years,

- non-profit organizations providing services of general interest and foundations with a period of operation of 5-10 years,

- non-profit organizations providing services of general interest and foundations with a period of operation of 10-15 years,

- non-profit organizations providing services of general interest and foundations with a duration of 15-20 years,

- non-profit organizations providing services of general interest and foundations with a duration of 20-25 years.

\section{Selection Group: Non-profit organizations providing services of general interest and foundations with a period of operation 1 - 5 years}

Table 1. Volume of funds raised by non-profit organizations providing services of general interest through tax allocation in 2019

\section{Non-profit organizations providing services of general interest}

\begin{tabular}{|l|c|}
\hline Name of non-profit organization & Assignment of 2\% income tax, year 2019 \\
\hline To children with cancer & $117289 €$ \\
\hline Man in danger & $20354 €$ \\
\hline KUBKO & $20008 €$ \\
\hline & Foundations \\
\hline Name of foundation & Assignment of 2\% income tax, year 2019 \\
\hline X-BIONIC®SPHERE Foundation & $64892 €$ \\
\hline F.P. Mitterbauer Foundation & $33445 €$ \\
\hline Gabor & $17106 €$ \\
\hline
\end{tabular}

Source: Own processing. 
2. Selection Group: Non-profit organizations providing services of general interest and foundations with a period of operation 5 - 10 years

Table 2. Volume of funds raised by non-profit organizations providing services of general interest through tax allocation in 2019

\begin{tabular}{|l|c|}
\hline \multicolumn{2}{|c|}{ Non-profit organizations providing services of general interest } \\
\hline Name of non-profit organization & Assignment of 2\% income tax, year 2019 \\
\hline Liberta & $233698 €$ \\
\hline The light of help & $97390 €$ \\
\hline ViaVitae & $34043 €$ \\
\hline & Foundations \\
\hline Name of foundation & Assignment of 2\% income tax, year 2019 \\
\hline Kia Motors Slovakia & $1423798 €$ \\
\hline EPH Foundation & $1300497 €$ \\
\hline Adeli Foundation & $1205344 €$ \\
\hline
\end{tabular}

Source: Own processing.

3. Selection Group: Non-profit organizations providing services of general interest and foundations with a period of operation 10 - 15 years

Table 3. Volume of funds raised by non-profit organizations providing services of general interest through tax allocation in 2019

\begin{tabular}{|l|c|}
\hline \multicolumn{2}{|c|}{ Non-profit organizations providing services of general interest } \\
\hline Name of non-profit organization & Assignment of 2\% income tax, year 2019 \\
\hline The good angel & $363606 €$ \\
\hline DEPAUL SLOVAKIA & $62334 €$ \\
\hline People to people & $36155 €$ \\
\hline & Foundations \\
\hline Name of foundation & Assignment of 2\% income tax, year 2019 \\
\hline VOLKSVAGEN SLOVAKIA Founation & $1597497 €$ \\
\hline Orange Foundation & $662984 €$ \\
\hline Allianz Foundation & $496037 €$ \\
\hline
\end{tabular}

Source: Own processing.

4. Selection Group: Non-profit organizations providing services of general interest and foundations with a period of operation 15 - 20 years

Table 4. Volume of funds raised by non-profit organizations providing services of general interest through tax allocation in 2019

\begin{tabular}{|l|c|}
\hline \multicolumn{2}{|c|}{ Non-profit organizations providing services of general interest } \\
\hline Name of non-profit organization & Assignment of 2\% income tax, year 2019 \\
\hline Flame & $872023 €$ \\
\hline For Lumen & $51265 €$ \\
\hline Ronald McDonald House Charity & $34515 €$ \\
\hline \multicolumn{2}{|c|}{ Foundations } \\
\hline Name of foundation & Assignment of 2\% income tax, year 2019 \\
\hline SPS Foundation & $1143912 €$ \\
\hline VUB Foundation & $1039912 €$ \\
\hline Slovak Savings Bank Foundation & $1007046 €$ \\
\hline Source: Own ref
\end{tabular}

Source: Own professing. 


\section{Selection Group: Non-profit organizations providing services of general interest and foundations with a period of operation 20 - 25 years}

Table 5. Volume of funds raised by non-profit organizations providing services of general interest through tax allocation in 2019

\begin{tabular}{|l|c|}
\hline \multicolumn{2}{|c|}{ Non-profit organizations providing services of general interest } \\
\hline Name of non-profit organization & Assignment of 2\% income tax, year 2019 \\
\hline The sun center & $13282 €$ \\
\hline New house & $11600 €$ \\
\hline The rehabilitation center - HARMONY & $9522 €$ \\
\hline \multicolumn{2}{|c|}{ Foundations } \\
\hline Name of foundation & Assignment of 2\% income tax, year 2019 \\
\hline SPS Foundation & $2661939 €$ \\
\hline VUB Foundation & $374134 €$ \\
\hline Slovak Savings Bank Foundation & $211955 €$ \\
\hline
\end{tabular}

Source: Own processing.

\section{Results}

Based on the analysis of selected subjects, we came to the results, which are described below according to the individual selection groups.

\section{Selection Group: Non-profit organizations providing services of general interest and foundations with a period of operation $1-5$ years}

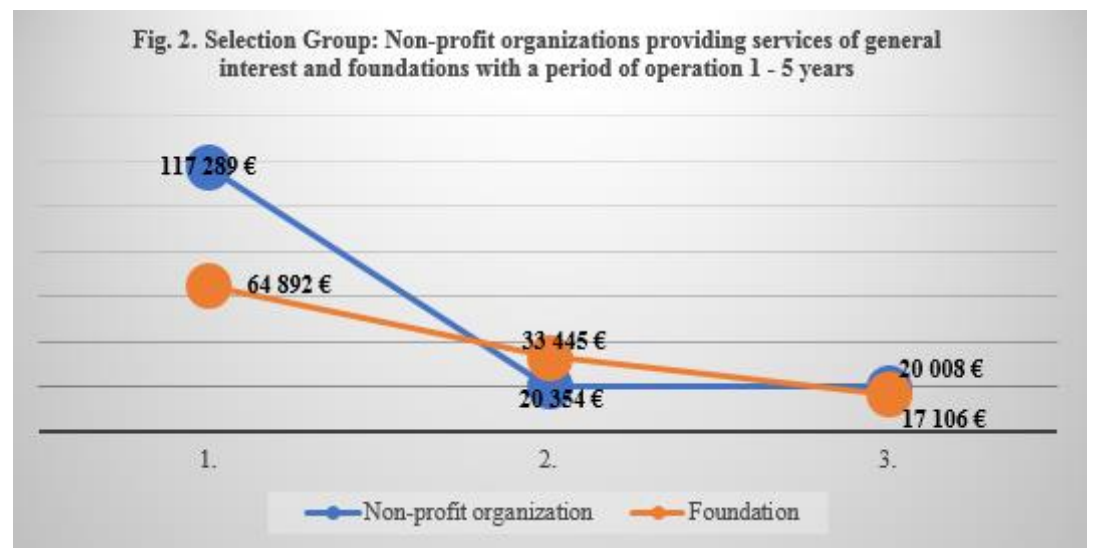

Fig. 2. Obtained amounts of funds of non-profit organizations providing services of general interest and foundations during their existence on the market in the range of 1-5 years.

Source: Own processing.

The difference in performance in terms of contributions collected through the form of tax allocation is the strongest in the case of non-profit organizations in the first - leading position in the national economy compared to the foundation. The non-profit organization To children with cancer was able to collect $€ 117,289$ through this form of funding, which in relative terms is $44,67 \%$ more than the foundation, which in 2019 occupied the leading position in this category in the non-profit sector in Slovakia. Non-profit organizations providing services of general interest in the second and third place noted the following differences. In the second place, the situation was more favourable in terms of performance in the case of the foundation, which in 2019 raised more funds through tax allocation compared to a non-profit organization providing services of general interest, namely by $39,14 \%$. In the third position, there was a difference in the funds obtained in favour of a 
non-profit organization providing services of general interest, which raised 14,50\% more funds compared to the foundation.

\section{Selection Group: Non-profit organizations providing services of general interest and foundations with a period of operation 5 - 10 years}

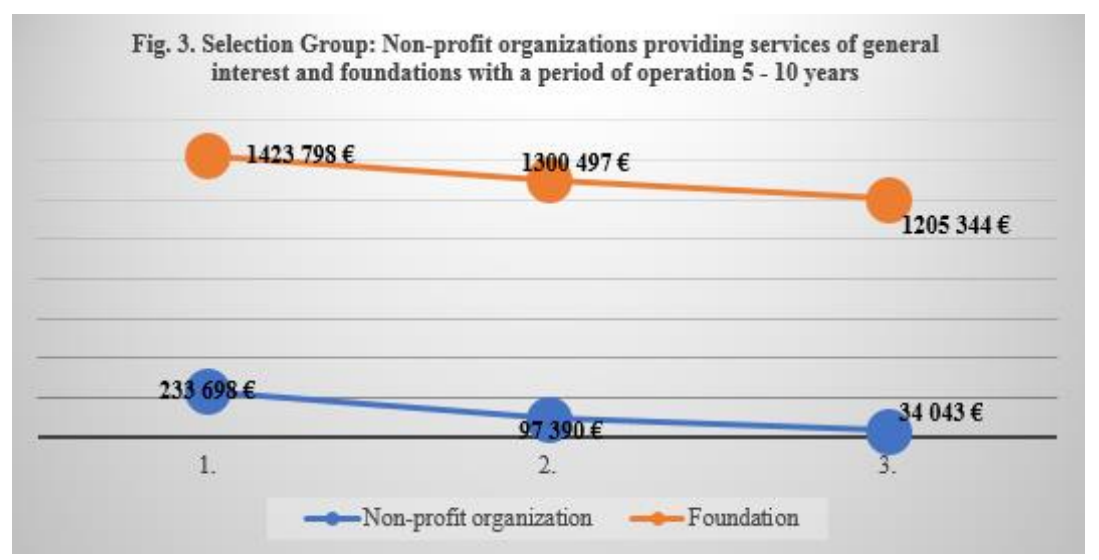

Fig. 3. Obtained amounts of funds of non-profit organizations providing services of general interest and foundations during their existence on the market in the range of $5-10$ years.

Source: Own processing.

According to the graph, it is clear that foundations were able to raise more funds in all three positions through tax allocation compared to non-profit organizations. In the first place in 2019 , the foundation led, which received $83,59 \%$ more funding than a non-profit organization. In the second place, the foundation led by $92,51 \%$ in the lead in the collected funds. In the third position, the foundation collected $97,18 \%$ more than a non-profit organization.

\section{Selection Group: Non-profit organizations providing services of general interest and foundations with a period of operation 10 - 15 years}

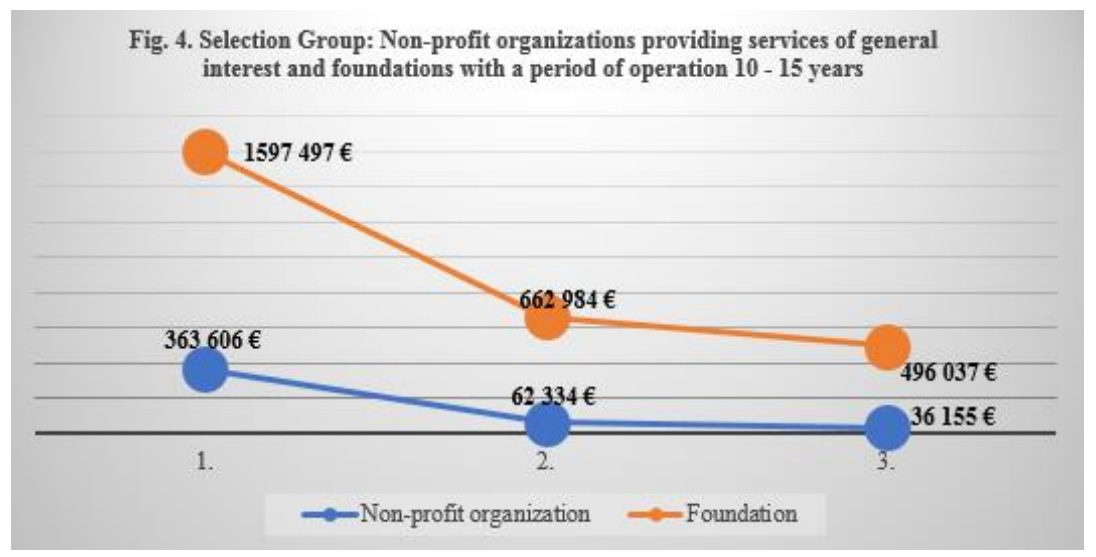

Fig. 4. Obtained amounts of funds of non-profit organizations providing services of general interest and foundations during their existence on the market in the range of $10-15$ years.

Source: Own processing.

In the case of non-profit sector entities with a period of 10-15 years, foundations were able to obtain more funds in comparison with non-profit organizations providing services of 
general interest. In the first position, the foundation was able to collect up to $77,24 \%$ more compared to a non-profit organization. In the second place, the difference in percentage expression was $90,60 \%$ higher in favour of the foundation. In the third position, the foundation raised $92,71 \%$ more funds than a non-profit organization.

\section{Selection Group: Non-profit organizations providing services of general interest and foundations with a period of operation 15 - 20 years}

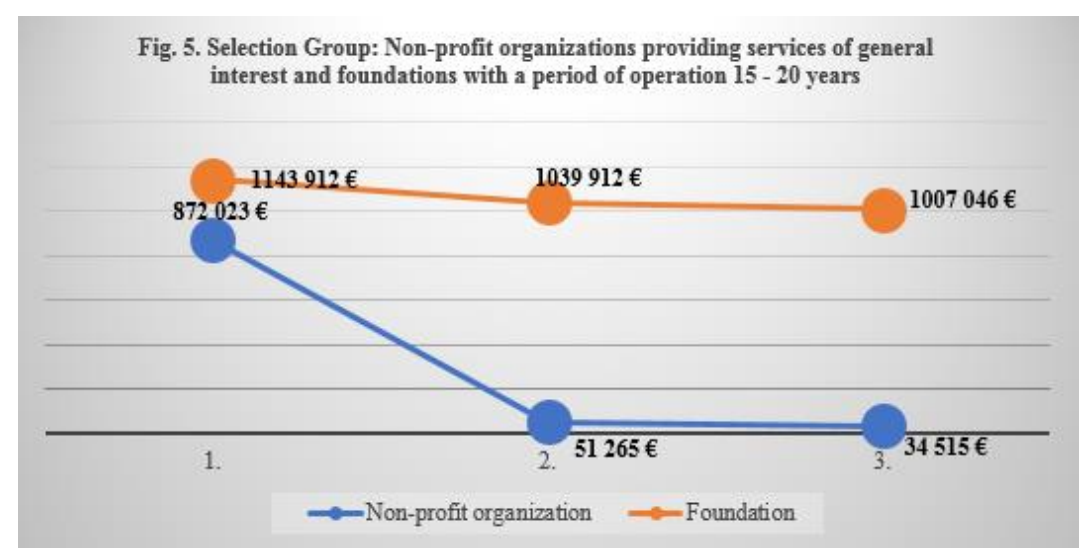

Fig. 5. Obtained amounts of funds of non-profit organizations providing services of general interest and foundations during their existence on the market in the range of $15-20$ years.

Source: Own processing.

Within the fourth selection group, they again led the foundations in the volume of funds raised. In the comparison of both entities in the first position was won by the foundation, which collected $23,77 \%$ more than the non-profit organization. In the second place, a deep drop in the non-profit organization was recorded, as the foundation managed to raise $95,07 \%$ more money. The third position brought a difference, which represented up to $96,57 \%$ greater success in the contributions received for foundations.

\section{Selection Group: Non-profit organizations providing services of general interest and foundations with a period of operation 20 - 25 years}

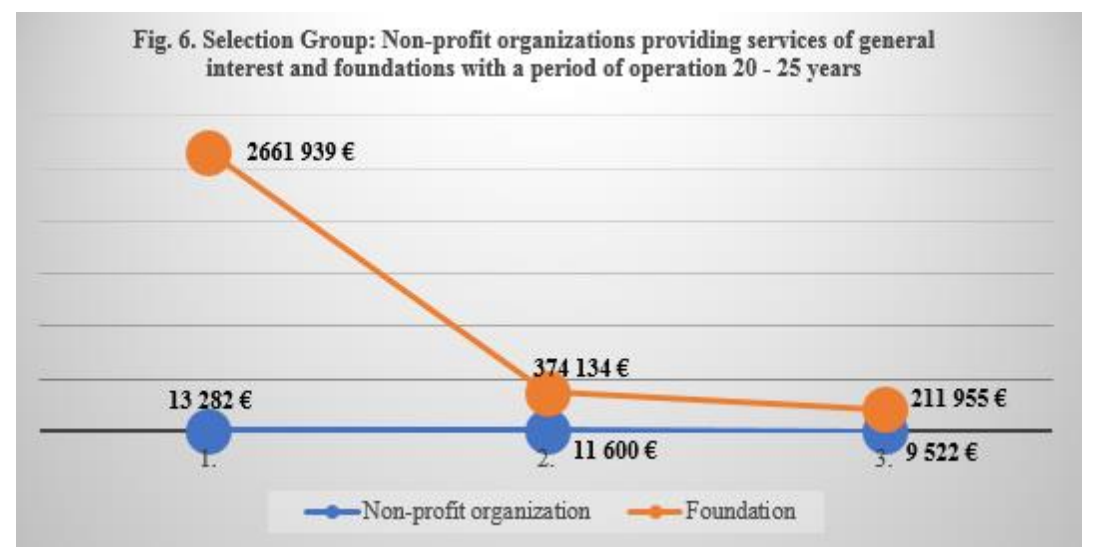

Fig. 6. Obtained amounts of funds of non-profit organizations providing services of general interest and foundations during their existence on the market in the range of $20-25$ years.

Source: Own processing. 
The last analysed group shows a deep drop in non-profit organizations compared to foundations. The foundation, with a period of operation on the market of 20-25 years, achieved up to $99,50 \%$ higher inflows of funds than a non-profit organization. In the second position, the foundation received $96,90 \%$ more funds, in the third position it was $95,51 \%$ more compared to a non-profit organization providing services of general interest.

\section{Discussion}

Only in one of the analysed groups did we reach a result where the non-profit organization was able to raise more funds through the tax allocation tool for 2019 than the foundation. Such a result occurred in the first analysed group with the existence of the subjects $1-5$ years in positions 2 and 3 . In other cases, the first place was always won by the foundation, which significantly exceeded the volume of funds collected by the foundation in individual cases. Regarding the evaluation of the financial performance of non-profit entities, we can state that in view of the extent of contributions collected, the vast majority of foundations were more successful and thus their performance is clearly stronger than in the conditions of non-profit organizations providing services of general interest. If we wanted to evaluate the performance of non-profit entities in terms of market life, we can say that the strongest non-profit organizations are in the category of life on the market $1-5$ years. Foundations with a period of operation of 15 to 20 years were able to raise the most funds, and a significant amount of funds was also obtained by the foundation in the first position with a period of existence on the market of 20 to 25 years. In the last analysed group - non-profit entities with a period of operation of 20-25 years, we can see a significant decline in non-profit organizations. In each of the above positions, there is a significant drop in performance of these entities compared to the foundation.

Based on the above analysis, we can state that in terms of market life, the most productive non-profit organizations in the group with a market life of $1-5$ years. On the contrary, their productivity is weakened with increasing market life. In the case of foundations, we could state that in the existence of 5 - 10 years and in the period of $10-15$ years there is a significantly higher performance and as can be seen from Fig. 6 . and in the case of the Pontis Foundation, which has a market life of 20-25 years, the performance of that foundation is very strong. In terms of building a lasting position in the market, the author Truffnell emphasizes the need to constantly monitoring the processes that affect the performance of each entity [20].

\section{Conclusion}

The issue of the article focuses on the performance of selected entities of the non-profit sector of the Slovak Republic in terms of the ability to secure funding to ensure its operation and existence in the market through the most important tool of these entities - tax assignment. Based on the analysis and subsequent comparison of the results of the analysed entities, we came to the conclusion that in the initial period of existence, i.e. 1-5 years were financially more efficient non-profit organizations, but in other periods of the foundation achieved better results compared to non-profit organizations providing services of general interest. In the last group of entities with a period of existence on the market of $20-25$ years, we came to the result that non-profit organizations lagged significantly behind the foundations and lose their performance. Based on the findings, we can state that the established hypothesis was not confirmed in all cases in terms of the existence of the entity on the market. 
The paper is an output of the science project VEGA 1/0544/19 Formation of the methodological platform to measure and assess the effectiveness and financial status of non-profit organizations in the Slovak Republic.

\section{References}

1. J. Crotty and S. Ljubownikow, Restrictive Institutions and Critical Resources: NonProfit Organisations and Volunteer Resources in the Russian Federation. Europe-Asia Studies, 72(1), 99-116 (2019)

2. K. Ajaz Khan, G. Çera, V. Netek, Perception of the selected business environment aspects by service firms. Journal of Tourism and Services, 10(19), 111-127 (2019)

3. J. Novotny and M. Lukes et al., Success factors of non-governmental non-profit organizations. Prague: Oeconomica (2008)

4. W. Zheng, N. Ni and D. Crilly, Non-profit organizations as a nexus between government and business: Evidence from Chinese charities. Strategic Management Journal, 10(4), 658-648 (2019)

5. L. Tetrevova, Verejna ekonomie. Prague: Professional Publishing (2008)

6. J. Rektorik et al., Non-profit sector organization. Prague: Ekopress (2007)

7. H. Majduchova, Non- profit organizations. Bratislava: Sprint dva (2009)

8. D. Vrtana and A. Krizanova, Brand Strategy of Successful Companies. Sustainable Economic Development And Application Of Innovation Management, 8007-8014 (2018)

9. R. Rajnoha and S. Lorincova, Strategic Management of Business Performance Based on Innovations and Information Support in Specific Conditions of Slovakia. Journal of Competitiveness. 7, 3-21 (2015)

10. Z. Bartosova, Guide to corporate philanthropy. Bratislava: Donors forum (2007)

11. T. Andjarwati, K. E. Susilo, A. K. Audah, Predictors of job satisfaction in non-profit organization. Polish Journal of Management Studies, 20(1), 19-28 (2019)

12. K. Valaskova, V. Bartosova, P. Kubala, Behavioural Aspects of the Financial DecisionMaking. Organizacija, 52(1), 22-32 (2019)

13. J. Salaga, V. Bartosova, E. Kicova, Economic Value Added as a measurement tool of financial performance. Procedia Economics and Finance, 26, 484-489 (2015)

14. K. Valaskova, P. Durana, P. Adamko, J. Jaros, Financial compass for Slovak enterprises: modeling economic stability of agricultural entities. Journal of Risk and Financial Management, 13(5), 92 (2020)

15. L. Shemyatikhina, K. Shipitsyna, M. Usheva, Marketing management of a non-profit organization. Ekonomicko-manazerske spektrum, 14(1), 19-29 (2020)

16. A. O. Carvalho, M. R. Ferreira, P. A. Silva, Partners in a caring society - a nonprofit organization case study. Economics and Sociology, 12(2), 129-146 (2019)

17. E. Alani, S. Kamarudin, L. Alrubaiee and R. Tavakoli, A model of the relationship between strategic orientation and product innovation under the mediating effect of customer knowledge management. Journal of International Studies, 12 (3), 232-242 (2019)

18. E. Nica, R. Miklencicova, E. Kicova, Intelligence-supported Workplace Decisions: Big Data Algorithmic Analytics, Sensory and Tracking Technologies, and Metabolism 
Monitors. Psychosociological Issues in Human Resource Management, 7(2), 31-36 (2019)

19. D. Ondrusek et al., Reader for non-profit organizations. Bratislava: Center for Conflict Prevention and Resolution (1998)

20. C. Tuffnell, P. Kral, P. Durana, T. Krulicky, Industry 4.0-based manufacturing systems: smart production, sustainable supply chain networks, and real-time process monitoring. Journal of Self-Governance and Management Economics, 7(2), 7-12 (2019) 